\title{
Epithelial localization of insulin-like growth factor binding protein 1 in the uterus of the rat during pregnancy, deciduoma-bearing pseudopregnancy and hormone treatment
}

\author{
S. Sadek ${ }^{1}$, T. G. Unterman ${ }^{2}$ and S. C. Bell ${ }^{1^{*}}$ \\ ${ }^{1}$ Department of Obstetrics and Gynaecology. The Medical School, University of Leicester, Leicester, \\ LE2 7LX, UK, and ${ }^{2}$ Department of Medicine, University of Illinois College of Medicine, Chicago,
} IL 60612, USA

\begin{abstract}
A monospecific antibody was used to determine the immunocytochemical localization of insulin-like growth factor binding protein 1 (IGFBP-1) in the rat uterus. Immunoreactive IGFBP-I was first detected from day 5 of pregnancy in the luminal and glandular epithelium. However, immunoreactivity was most intense from day 6 in the glandular epithelium, where it was associated with apically located granules. Immunoreactive glands were located only in non-decidualized endometrium, which was limited at the implant site to a thin basal layer by growth of the antimesometrial decidua from day 7 . However, glands and associated immunoreactive IGFBP-1 were prominent in the inter-implant sites until day 9, although they were detected throughout pregnancy. Similar reactivity was detected in the glands of the basal endometrium in deciduomata-bearing animals, but these decreased in number from day 7 of pseudopregnancy. No immunoreactivity was detected during the oestrous cycle but could be induced in ovariectomized animals by sequential oestradiol and oestradiol plus progesterone treatment. The observations were consistent with IGFBP-I representing a secretory product of the glandular epithelium and could either play a role in development of the trophoblastic component of the conceptus during the pre-placental period of anti-mesometrial implantation or in the endometrium acting as an inhibitor of local IGF-I action and in either case by transporting IGF-I from the stromal to the glandular luminal environment.
\end{abstract}

\section{Introduction}

The insulin-like growth factors (IGFs) are involved in tissue growth and differentiation and appear to act via paracrine and autocrine as well as classical endocrine mechanisms (Rotwein, 1991). However, it is apparent that the systemic and local tissue bioavailability of IGF is affected by the action of members of a family of soluble, low molecular mass, highaffinity insulin-like growth factor binding proteins which exhibit differential tissue expression, compartmental distribution and ligand specificity (Rosenfeld et al., 1990; Shimasaki and Ling, 1991). The production of one member of this family, IGF binding protein-I (IGFBP-1), previously called 'endometrial protein 14', 'pregnancy-associated endometrial alpha1-globulin' and 'placental protein 12' (Bell, 1986), is predominantly associated with pregnancy in humans and in non-human primates. In these species, IGFBP-I represents the major secretory product of the gestational decidualized endometrium, or decidua (Bell et al., 1985; Fazleabas et al., 1989a).

In early human pregnancy, differentiation of the endometrial stromal cells to decidual cells, initially involving the superficial

${ }^{*}$ Correspondence and reprint requests.

Received 6 July 1993. endometrium, progressively involves the deeper endometrium. The glandular component of the deeper endometrium, in which secretion has been induced during the menstrual cycle, has involuted by the end of the first trimester.

In non-human primates, in which decidual cell differentiation is induced by the embryo, the glands persist for longer. IGFBP-1 is the major product of the decidual cell throughout pregnancy in these species, although IGFBP-1 expression has also been localized to the secretory glandular epithelium of the non-decidualized endometrium, during pregnancy in humans (Waites et al., 1988; 1989) and initiated during the menstrual cycle in non-human primates (Fazleabas et al., 1989b).

Although secretory differentiation of the glandular epithelium is a common feature of many placental species, decidual cell differentiation or decidualization of the endometrial stroma appears to occur only in those species in which placentation involves invasion of the stromal compartment of the endometrium (Bell, 1983). The production of IGFBP-1 by the gestational endometrium in these species may represent a conserved feature and it has been proposed to fulfil an essential function in the regulation of IGF-I action at the maternofetal interface during embryonic implantation and placental development (Bell, 1989).

Downloaded from Bioscientifica.com at 04/26/2023 01:09:24PM 
Studies have been performed on small laboratory animals such as rats to facilitate study of the physiological roles of the gestational endometrium, particularly the decidual cell and its products, in a more direct way. However, in this species, the major secretory product of decidual tissue is a charge variant of the hepatic 'acute-phase' $\alpha_{2}$-macroglobulin or $\alpha$-macrofetoprotein termed 'decidualization-associated protein' (Bell, 1979a, b), and attempts to identify IGFBPs as major secretory products have been unsuccessful (S. Sadek and S. C. Bell, unpublished observations). By the use of a specific rat IGFBP-1 cDNA, mRNA for IGFBP-1 has been shown to be transiently expressed in artificially induced deciduomal tissue during its early development. However, this mRNA is localized to the minor luminal and glandular epithelium component and not to decidual cells (Croze et al., 1990).

In this present study we used a specific antiserum to rat IGFBP-I in an attempt to detect its production and localization during pregnancy, to assess its significance in IGF action and placental development.

\section{Materials and Methods}

\section{Animals and treatments}

Wistar rats weighing 200-250 g were housed under standard conditions in a $14 \mathrm{~h}$ light: $10 \mathrm{~h}$ dark cycle, and had access to stock diet and water ad libitum. Vaginal smears were taken daily from a group of female rats and examined under a microscope to determine the stage of the oestrous cycle. Two animals were identified in each of pro-oestrus, oestrus, metoestrus, day 1 dioestrus and day 2 dioestrus of the cycle. Female rats were caged singly overnight with males and detection of a vaginal plug in the morning was counted as day 1 of pregnancy. Deciduomata were induced in pregnant rats in the afternoon of day 5 . Under fluthane anaesthesia, the ovarian end of each uterine horn was exteriorized through a flank incision and $0.5 \mathrm{ml}$ of arachis oil injected into the uterine lumen. When deciduomata were induced only unilaterally, a double ligature was placed around the oviduct of one uterine horn on day 2 of the pregnancy, and the contralateral horn injected with arachis oil on day 5. In another group of rats, both ovaries were excised by the same surgical approach. After two weeks the ovariectomized rats were allocated to groups and given: (1) $1 \mu \mathrm{g}$ oestradiol (Sigma, Poole) in $0.2 \mathrm{ml}$ arachis oil s.c. for 3 days; (2) $4 \mathrm{mg}$ progesterone (Sigma) in $0.2 \mathrm{ml}$ arachis oil s.c. for 3 days; (3) $1 \mu \mathrm{g}$ oestradiol for 3 days followed by $4 \mathrm{mg}$ progesterone for 3 days; (4) $1 \mu \mathrm{g}$ oestradiol for 3 days followed by $1 \mu \mathrm{g}$ oestradiol plus $4 \mathrm{mg}$ progesterone for 3 days; and (5) arachis oil $0.2 \mathrm{ml}$ s.c. for 3 days.

All experimental animals were killed by cervical dislocation and the uterine horns were dissected and fixed immediately in $10 \%$ formal saline for $24 \mathrm{~h}$. Where necessary the implant site tissues were marked with Indian ink and embedded in paraffin wax orientated to enable the implant sites to be sectioned either transversely or longitudinally.

\section{Immunocytochemistry}

Paraffin wax sections $(4 \mu \mathrm{m})$ were taken onto silane-coated slides and examined after staining with haematoxylin and eosin. A polyclonal rabbit anti-rat IGFBP-I serum was produced against IGFBP-I purified from the conditioned medium of the rat hepatoma cell line $\mathrm{H} 4 \mathrm{IIEC} 3$ and its specificity confirmed by western blotting techniques (Unterman et al., 1990, 1993). This was used as the primary antibody in a standard immunocytochemical procedure using a strept avidin/biotin complex (Dako, High Wycombe, Bucks), for the substrate reaction with fast red. Slides were counterstained with Meyer's haematoxylin. In a titration experiment a dilution of 1:500 was found to be the optimal primary antibody titre. Initial experiments demonstrated that pepsinization enhanced the immunoreactivity without altering the specificity. The immunohistochemical specificity of the antiserum was tested against: (1) normal rabbit serum at equivalent titre range; (2) absorbed antiserum. The antiserum was incubated in excess of either purified IGFBP-I or the antigen-containing conditioned medium at room temperature overnight, centrifuged at $11600 \mathrm{~g}$ for $10 \mathrm{~min}$ and the supernatant used at a dilution equivalent to 1:500 dilution of the original antiserum.

\section{Results}

\section{Immunoreactive IGFBP-1 in the uterus during pregnancy}

Initial studies were performed with transverse sections; these were sections through the middle of implantation sites

Fig. 1. Photomicrographs of transverse sections of implant sites immunostained with antiserum to insulin-like growth factor binding protein 1 (IGFBP-1) using the Strept Avidin/Biotin method and counterstaining with haematoxylin. (a) Day 5 of pregnancy. Note immunostained condensed material within the glandular lumen. (b) Day 7 of pregnancy. Intense staining within the apical aspect of the majority of glands and their epithelial cells. (c) Day 7 of pregnancy: serial section of region shown in (b) but stained with antiserum absorbed IGFBP-1; no immunostaining detected. (d) Higher magnification of gland shown in (b) illustrating granular nature of immunostaining structures within glandular epithelium. (e) Day 7 of pregnancy. Glandular epithelium illustrating distribution of immunostained structures (arrowheads) clustering in the perinuclear area of some cells. ( $\mathrm{f}$ ) Day 7 of pregnancy: luminal epithelium of implant site lumen immunostained, but with less intensity than were glands shown in (d). ( $g$ ) Day 9 of pregnancy. Antimesometrial aspect of implant site showing conceptus (C), remaining mesometrial aspect of lumen (L), antimesometrial decidua (AMD) and underlying thin basal endometrium containing sparse immunostained glands (arrowheads indicating basal endometrium). ( $\mathrm{h}$ ) Day 9 of pregnancy: higher magnification of immunostained gland in (g) showing antimesometrial decidua (AMD) and basal endometrium (BE). (i) Day 9 of pregnancy: immunostaining of luminal epithelium remaining in the mesometrial aspect of the lumen (L). Slight immunostaining of the luminal contents was noted. (j) Day 12 of pregnancy: note luminal epithelium (LE) now covering basal endometrium (BE) containing immunostained gland (arrowhead) and separating it from the thin antimesometrial decidua (AMD). Note trophoblast giant cell (TGC). Scale bars represent $20 \mu \mathrm{m}$ in (a), (d), (e) and (f), $50 \mu \mathrm{m}$ in (b), (c), (h), (i) and (j), and $1 \mathrm{~mm}$ in (g). 

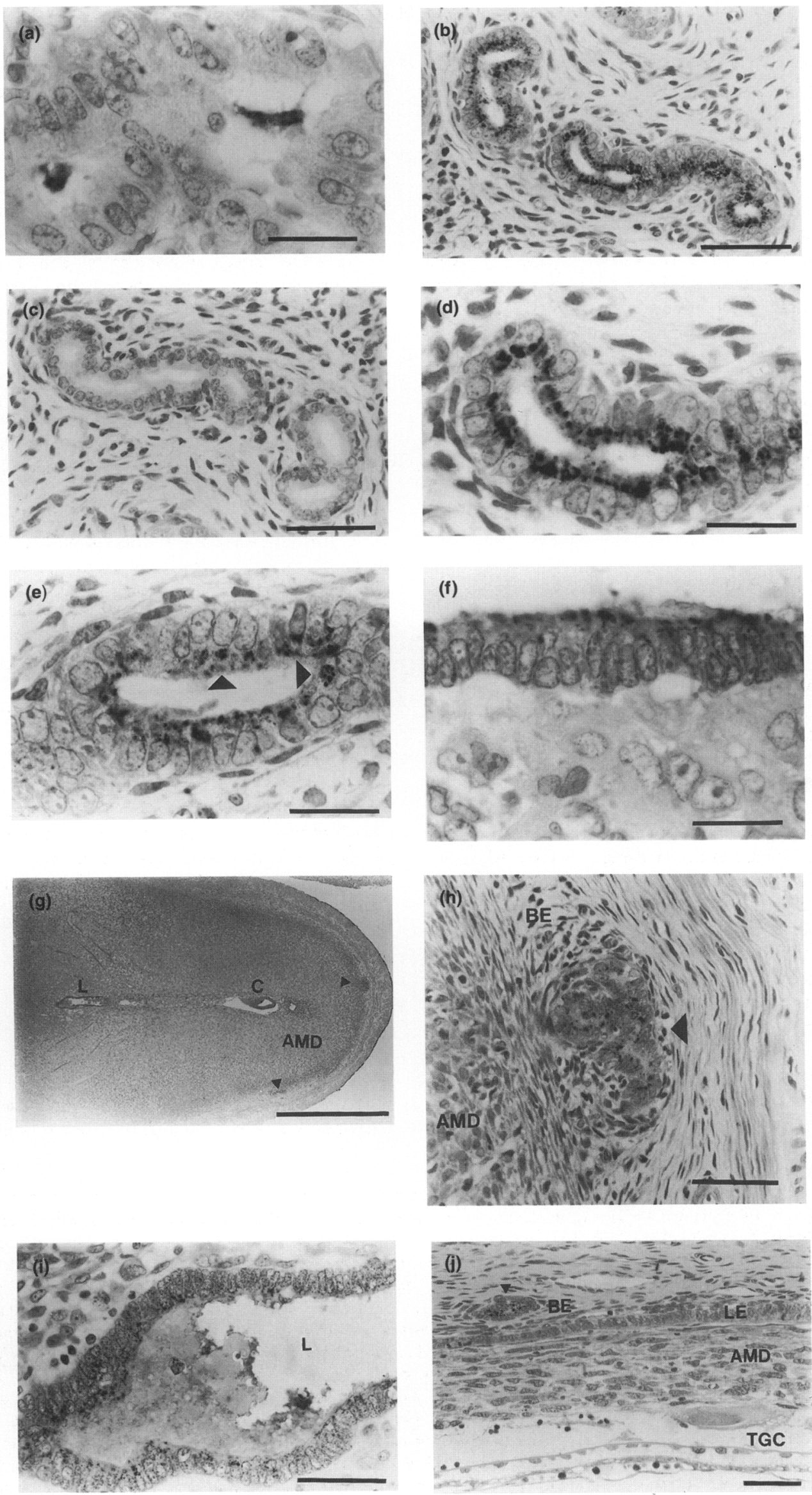

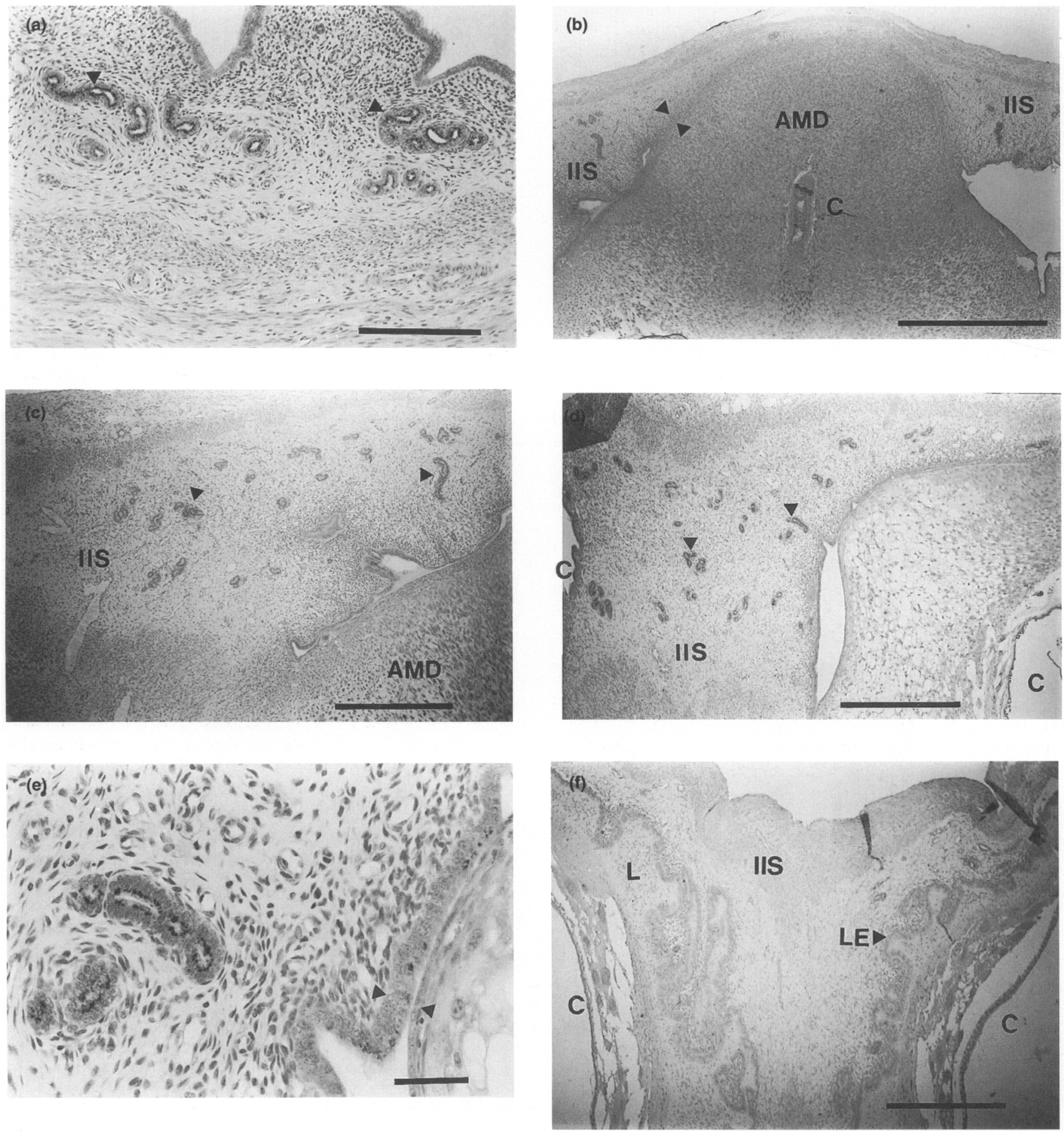
on and after day 7. No immunoreactivity was detected in sections on days 1 and 3 at any antibody titre tested. On day 5, the day of implantation, weak staining was detected on condensed secretory material within the lumen of some glands (Fig. Ia). Weaker staining was detected in the cytoplasm of a few glandular epithelial cells. On day 7 , intense immunoreactivity was detected in the apical cytoplasm of most uterine glands, in the form of discrete spherical granular structures distributed from the apical side of the nucleus to the luminal membrane (Fig. $1 \mathrm{~b}, \mathrm{~d}$ ); some were seen as discrete clusters adjacent to the apical surface of the nucleus (Fig. Ie). No staining was detected in sequential sections incubated with either non-immune rabbit serum or antiserum absorbed with IGFBP-1 (Fig. Ic). Uterine glands were found lateral and basal to the antimesometrial decidua in the layer of nondecidualized endometrium. Similar staining intracellular bodies, albeit less intense and frequent, were detected in cells of the luminal epithelium (Fig. If). No staining was detected in any other cell type, including those of the antimesometrial decidua.

On day 9, glands were also positively stained for immunoreactive IGFBP-I but were less frequent as the basal endometrium became compressed anti-mesometrially (Fig. $\mathrm{Ig}, \mathrm{h}$ ). A layer of condensed cord-like stromal cells separated the gland-free antimesometrial decidua from the basal nondecidualized endometrium. Staining was still detected in cells of the remaining intact luminal epithelium which was found in the mesometrial aspect of the implantation chamber (Fig. 1i). On day 11 , the antimesometrial decidua ruptured from the basal endometrium at this zone and on day 12 in some sections the basal endometrium was now covered with a new luminal epithelium which was in contact with a degenerating antimesometrial decidual layer (Fig. 1j).

On day 14, the giant trophoblast cell layer was separated from the basal endometrium by a few necrotic cells and debris. The appearance of the luminal epithelium was different from at day 12, was different to glandular structures and corresponded to the presence of copious secretion within the uterine lumen. Throughout this period, glands were detected infrequently in the thin basal endometrium but were immunoreactive for IGFBP-1. For the remainder of pregnancy, as the endometrium became further stretched, glandular structures were rarely detected. In none of these sections on or after day 7 was the upper openings of the glandular structures detected.

A similar study was performed with uteri sectioned longitudinally through the gestation sacs on days 6-13 to include the inter-implant sites. From day 6 in inter-implant regions, intense staining bodies were detected in most epithelial cells of the uterine glands, which decreased in cells towards glandular openings and in the contiguous luminal epithelium (Fig. 2a). At all stages, staining immunoreactivity was detected in the apical cytoplasm of most uterine glands, in the form of discrete spherical granular structures in the apical cytoplasm. It was apparent that owing to the growth the antimesometrial decidua displaced glandular structures laterally.

From day 9 similar staining of non-decidualized interimplant regions was detected with the lumen of glands of the endometrium adjacent to the conceptus unit opening into an area which also faces the surface of the lateral side of the antimesometrial decidual capsule (Fig. 2b, c). As the decidua regresses to form the capsule and with growth of the conceptus, the immunoreactive luminal epithelium and gland structures were observed to abut upon the lateral decidua (Fig. $2 \mathrm{~d}$, e). From day 13 the interimplant lumen almost disappeared and owing to growth of the conceptus the inter-implant endometrium became drawn over the conceptus-containing capsule. Although less frequent, glands stained for IGFBP-I (Fig. 2f).

Immunoreactive IGFBP-1 in the uterus during the oestrous cycle in hormone-treated and deciduomata-bearing animals

Immunoreactivity was not detected in uterine sections obtained at any stage during the oestrous cycle at any titre of antiserum (Fig. 3a-d). In hormone-treated ovariectomized animals, immunoreactivity was detected only after sequential oestradiol and oestradiol plus progesterone treatment (Fig. $3 \mathrm{e}-\mathrm{h})$. The staining was restricted to glandular and luminal epithelium and the secretions. Immunoreactive intracellular bodies were detected in glandular epithelial cells similar to those detected during pregnancy albeit at lower intensity and frequency.

In deciduomata-bearing horns, immunoreactive IGFBP-1 was detected throughout the period of pseudopregnancy Fig. 2. Photomicrographs of longitudinal sections of uteri during pregnancy, immunostained with antiserum to insulin-like growth factor binding
protein I (IGFBP-1) using the Strept Avidin/Biotin method and counterstaining with haematoxylin. (a) Day 7 of pregnancy. Majority of glands
in non-decidualized endometrium are intensely immunostained (arrowheads). (b) Day 9 of pregnancy. Conceptus (C) embedded within
antimesometrial decidua (AMD). Note condensed layer of cells (arrowheads) between decidualized AMD and underlying thin non-decidualized
endometrium with sparse glands. Lateral to implant site non-decidualized endometrium of the inter-implant site (IIS) region abuts onto lateral
aspect of the AMD. (c) Day 9 of pregnancy. Higher magnification of lateral area in (b). Note more numerous immunostained glands in
inter-implant site region with luminal epithelium and gland openings abutting onto the antimesometrial decidual capsule (immunostained glands
arrowed). The capsule is covered with squamous epithelium. (d) Day 11 of pregnancy. Inter-implant site region between two conceptuses (C) and
containing immunostained glands and abutting onto lateral decidua of the capsule. Area of fixation shrinkage shows nature of interface with
endometrial luminal epithelium opposite to squamous epithelium of capsule (arrowheads). (e) Day 11 of pregnancy. Higher magnification of
interface site in (d). Note immunostained apical structures in glandular epithelium and to a lesser extent in the luminal epithelium opposed to the
capsular epithelium covering the decidua (arrowhead). (f) Day 13 of pregnancy. Inter-implant site (IIS) between two conceptuses (C) containing
immunostained glands. The luminal epithelium (LE) at this stage appears hypertrophied and copious secretory material is found in the lumen (L).
Scale bars represent $1 \mathrm{~mm}$ in (b), $500 \mu \mathrm{m}$ in (c), (d) and (f), $200 \mu \mathrm{m}$ in (a) and $50 \mu \mathrm{m}$ in (e). 
examined. The immunoreactivity was detected in epithelial cells of the glands of the non-decidualized endometrium basal and lateral to the antimesometrial decidua (Fig. 3i,j). Most intense reactivity was detected $I$ day after induction of decidualization, that is on day 6. Thereafter, the number of glands and associated immunoreactivity decreased with the thinning of the antimesometrial basal non-decidualized endometrium.

\section{Discussion}

A specific antiserum to rat IGFBP-1 was used to localize immunoreactive protein specifically to the luminal and glandular epithelium of the uterus during pregnancy. At all stages immunoreactivity was most intense within the glandular epithelium. Within the epithelium immunoreactivity was detected only as intensely stained granules or vesicles in clusters apical to the nucleus and distributed apically toward the luminal cell membrane. None was detected either basally or laterally to the nucleus. These features were consistent with the contention that IGFBP-1 is a secretory product of glandular and luminal epithelium and destined for secretion into the glandular and uterine lumen. However, only on day 5 was staining detected in the glandular lumen and this may reflect the soluble nature of IGFBP-1 and the secretions at other stages of pregnancy. However, there was light staining of the contents of the lumen of the implantation chamber on days 7 and 9 .

No immunoreactivity was detected in any type of decidual cell, anti-mesometrial, lateral, or mesometrial. Although initiation of IGFBP-I production appeared to be in the uterine glands on day 5 of pregnancy, maximal intensity was detected in most glands throughout the uterus on day $6,24 \mathrm{~h}$ after implantation. Throughout the remainder of pregnancy most glands, when detected, were immunoreactive for IGFBP-I. Given that the glands were localized in the antimesometrial and lateral stroma of the uterus of non-pregnant animals and that glandular structures were not detected in the decidualized stroma, the pattern of IGFBP-I immunoreactivity in the uterus detected in transverse and longitudinal sections can be accounted for by the effect of the morphogenesis of implantation sites upon the uterus. Thus during the first phase of implantation, which occurs from day 5 to day 9, the antimesometrial decidua which surrounds the embryo and forms the initial implantation chamber limits the non-decidualized gland-containing endometrium to a thin baso-lateral layer. This would explain the apparent early decrease in positive glands in transverse sections of the implant site from day 7 to day 9 during which antimesometrial decidual development is maximal and may also explain the observations of Croze et al. (1990) that IGFBP-1 expression is induced on day 6 and subsequently IGFBP-I mRNA decreases as decidualization progresses.

In the study of Croze et al. decidualization was artificially induced throughout the uterus; no gland-containing interimplant regions would therefore develop. The results reported here also demonstrated this progressive decline in the frequency of immunoreactive glands in the compressed basal endometrium from day 6. However, during pregnancy, as revealed by examination of longitudinal sections, it was apparent that immunoreactive uterine glands are numerous in the inter-implant region, particularly from day 6 to day 9, and in areas of non-decidualized endometrium abutting upon the lateral aspects of the decidua. From day 9, the growth of the conceptus antimesometrially pulls the inter-implant region over the decidua-conceptus such that the inter-implant site contracts and the endometrium containing glands come into direct contact with the decidual capsule. With this stretching, the endometrium thins and glands become sparse except at the region between conceptuses. This phenomenon has been described in detail by Welsh and Enders (1983).

IGFBP-1 production in pregnancy in rats, unlike in humans and non-human primates, is restricted solely to the glandular epithelium and its localization to the inter-implant sites primarily between days 6 and 9 may indicate that it does not have a direct function in implantation. These observations suggest two, but not necessarily mutually exclusive, roles for glandular IGFBP-1. The first function could link glandular IGFBP-I secretion with the development of the conceptus during its phase of antimesometrial implantation from day 5 to day 9/10 of pregnancy. During this period of maximal IGFBP-I expression, the embryo lies 'free' in an implantation chamber which is contiguous with the inter-implant lumen (Welsh and Enders 1983) and thus the trophoblast component of the conceptus could be accessible to IGFBP-1-containing luminal secretions. It is possible that uterine glandular secretion of IGFBP-1 represents a carrier system transporting IGF-I from the adjacent stroma (Croze et al., 1990), via the lumen, to the trophoblast of the conceptus during its period of development within the implantation chamber and prior to its interstitial invasion of the mesometrial decidua.

On the basis of studies of IGF-1 expression in the murine uterus, Kapur et al. (1992) proposed that uterine IGF-I may exert paracrine effects upon embryonic development mediated via their IGF-I receptors. It is also relevant to note that other factors involved in control of growth have been demonstrated to originate in the glandular epithelium after implantation in

Fig. 3. Photomicrographs of transverse sections of uteri obtained from the oestrous cycle, hormone-treated ovariectomized and deciduomabearing animals immunostained with antiserum to insulin-like growth factor binding protein I (IGFBP-1) using the Strept Avidin/Biotin method and counterstaining with haematoxylin. (a) Pro-oestrus; (b) oestrus; (c) dioestrus day 1 ; (d) dioestrus day 2; (e) oestradiol-treated ovariectomized animals; (f) progesterone-treated ovariectomized animals. (g) Oestradiol plus progesterone treated ovariectomized animals. (h) Oestradiol, oestradiol plus progesterone treated ovariectomized animals. Note immunostained luminal secretions and intracellular structures. (i) Oil-induced deciduoma on day 7 of pseudopregnancy. Antimesometrial decidua (AMD) with thin peripheral non-decidualized endometrium (E) containing immunostaining glands (arrowheads). (j) Higher magnification of immunoreactive gland in (i). Scale bars represent $50 \mu \mathrm{m}$ except for (i) where it represents $500 \mu \mathrm{m}$. 

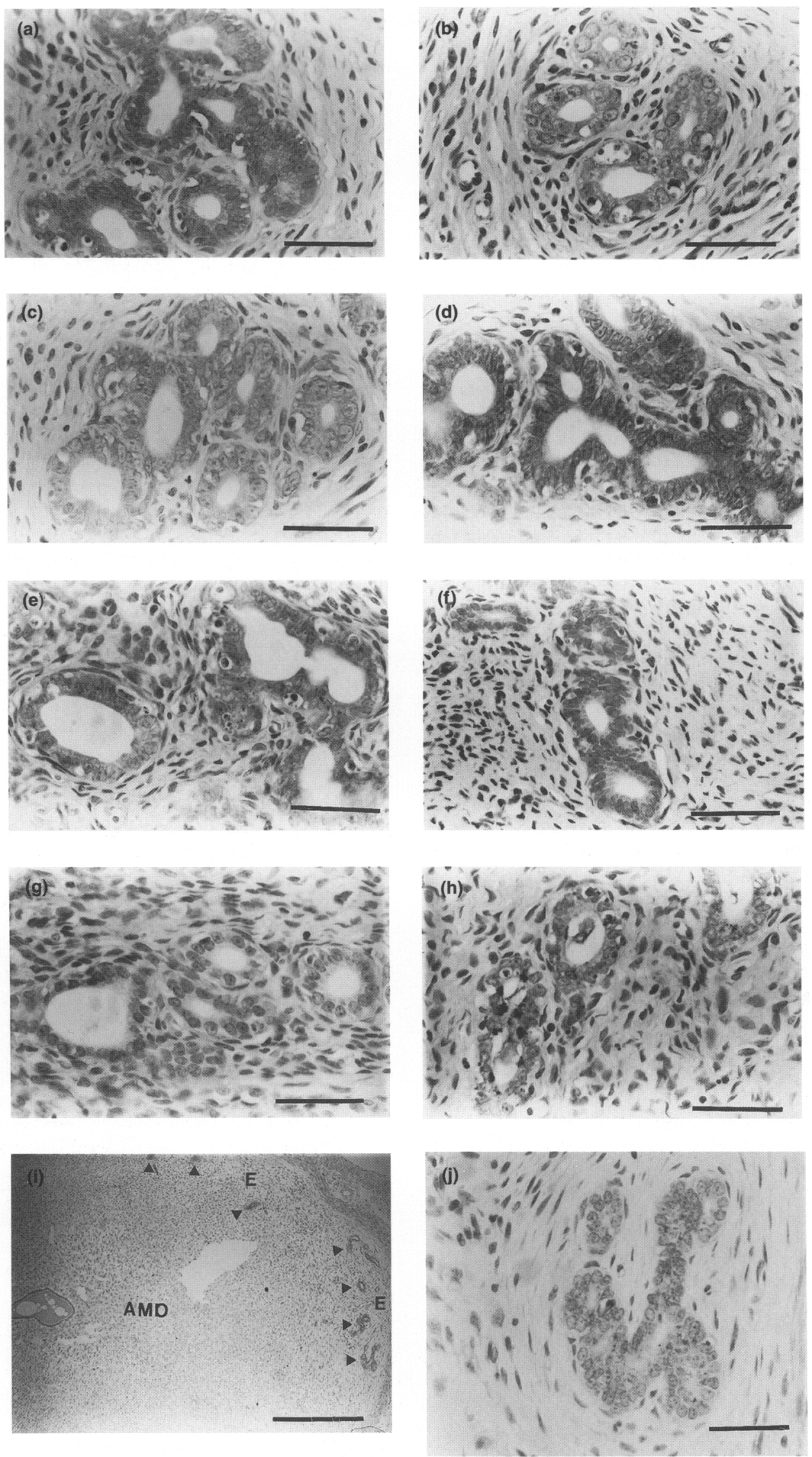
rodents and for which receptors exist in the conceptus, for example colony-stimulating factor I (Arceci et al., 1989).

A second role relates to the proposal of Croze ef al. (1990) that IGFBP-I expression in the glandular and luminal epithelium, which is surrounded by stromal regions of high IGF-I expression, inhibits the mitogenic action of IGF-I in the endometrium and that this allows stromal-decidual cell differentiation. Studies in rodents and humans suggest that IGF-I does mediate the mitogenic action of oestradiol in the endometrium (Guidice et al., 1993; Murphy et al., 1987). The observations in the study reported here of glandular secretion could provide a mechanism whereby IGFBP-1 inhibits the local mitogenic action of IGF-I, as IGFBP-1 may remove IGF-I from the stroma, its site of synthesis, and transfer it into the lumen. However, our observations do not support a requirement of this mitogenic inhibition for stromal-decidual cell differentiation. Indeed the process of decidualization involves stromal proliferation as well as differentiation (Bell, 1983) and evidence indicates that it may involve the action of different growth factors such as IGF-II (Guidice et al, 1993) or transforming growth factor $\alpha$ (TGF- $\alpha$ ) (Bonovissuto et al., 1992). Maximal epithelial staining was detected in non-decidualized gland-containing interimplant regions during pregnancy and the loss of expression in the implant site appeared to result from the progressive decidualization and compression of glands at this latter site. It is more likely that this phenomenon is involved in regulating oestradiol action in the non-decidualized endometrium of inter-implant regions. Endometrial IGF-I expression in rats is regulated by oestradiol (Ghahary et al., 1990); induction of IGFBP-1 expression in the epithelium by progesterone may therefore provide a mechanism whereby progesterone can inhibit mitogenic effects of oestradiol in the non-decidualized areas without preventing other actions of oestradiol within the decidua.

The failure to detect IGFBP-I in the rat decidua, in direct contrast to the situation in humans, may indicate that the decidual cell does not have a conserved role in the modulation of IGF action. However human $\alpha_{2}$-macroglobulin has been reported to bind a wide variety of cytokines and growth factors (Chu et al., 1991; Hall et al., 1992; Matsuda et al., 1989) and we have recently demonstrated similar properties for the decidual-derived $\alpha_{2}$-macroglobulin (Correia da Silva et al., 1993). Further studies are in progress to examine the relative roles of the glandular epithelium and decidual cell in IGF action in pregnancy in rats.

The authors wish to thank the Biomedical Services Department, University of Leicester for support with the animal husbandry, the Trent Regional Health Authority for financial support of S. Sadek and S. Thomson for secretarial assistance.

\section{References}

Arceci RJ, Shanahan F, Stanley ER and Pollard JW (1989) Temporal expression of and location of colony-stimulating factor $I$ (CSF-1) and its receptor in the female reproductive tract are consistent with CSF-I regulated placental development Proceedings of the National Academy of Sciences USA 86 $8818-8822$
Bell SC (1979a) Immunochemical identity of 'decidualization-associated protein' and $\alpha 2$-macroglobulin in the pregnant rat Journal of Reproductive Immunology 1 193-206

Bell SC (1979b) Synthesis of decidualization-associated protein in tissues of the rat uterus and placenta during pregnancy Joumal of Reproduction and Fertility $56255-262$

Bell SC (1983) Decidualization: regional differentiation and associated function Oxford Reviews of Reproductive Biology 5 220-271

Bell SC (1986) Secretory endometrial and decidual proteins: studies and clinical significance of a maternally-derived group of pregnancy-associated serum proteins Human Reproduction 1 129-143

Bell SC (1989) Decidualization and insulin-like growth factor (IGF) binding protein: implications for its role in stromal cell differentiation and the decidual cell in haemochorial placentation Human Reproduction 4 $125-130$

Bell SC, Hales MW, Patel S, Kirwan PH and Drife JO (1985) Protein synthesis and secretion by the human endometrium and decidua during early pregnancy British Journal of Obstetrics and Gynaecology 92 793-803

Bonovissuto AC, Lala PK, Kennedy TG, Nygard K, Lee DC and Han VKM (1992) Induction of transforming factor-alpha gene expression in rat decidua is independent of the conceptus Biology of Reproduction 46 607-616

Chu CT, Rubenstein DS, Enghild JJ and Pizzo SV (1991) Mechanism of insulin incorporation into alpha2-macroglobulin: implications for the study of peptide and growth factor binding Biochemistry 30 1551-1560

Correia da Silva G, Teixeira N and Bell SC (1993) 'Decidualization-associated protein', a decidual tissue-derived variant of $\alpha$-macroglobulin in the rat, binds IL-6 Joumal of Reproduction and Fertility Abstract Series 1194

Croze F, Kennedy TG, Schroedter IC, Friesen HG and Murphy LJ (1990) Expression of insulin-like growth factor-1 and insulin-like growth factorbinding protein-1 in the rat uterus during decidualization Endocrinology 127 1995-2000

Fazleabas AT, Verhage HG, Waites G and Bell SC (1989a) Characterization of an insulin-like growth factor binding protein, analogous to human pregnancyassociated secreted endometrial alpha 1-globulin, in decidua of the baboon (Papio anubis) placenta Biology of Reproduction 40 873-885

Fazleabas AT, Jaffe RC, Verhage HG, Waites G and Bell SC (1989b) An insulin-like growth factor-binding protein in the baboon (Papio anubis) endometrium: synthesis, immunocytochemical localization, and hormonal regulation Endocrinology 124 2321 2329

Ghahary A, Chakrabarti S and Murphy LJ (1990) Localization of the sites of synthesis and action of insulin-like growth factor- $I$ in the rat uterus Molecular Endocrinology 4 191-195

Guidice LC, Dsupin BA, Jin IH, Vu TH and Hoffman AR (1993) Differential expression of messenger ribonucleic acids encoding insulin-like growth factors and their receptors in human uterine endometrium and decidua Journal of Clinical Endocrinology and Metabolism 76 1115-1122

Hall SW, LaMarre J, Marshall LB, Hayes MA and Gonias SL (1992) Binding of transforming growth factor-beta1 to methylamine modified alpha2macroglobulin and to binary and ternary alpha2-macroglobulin-proteinase complexes Biochemical Journal 281 569-575

Kapur S, Tamada H, Dey SK and Andrews GK (1992) Expression of insulin-like growth factor-I (IGF-I) and its receptor in the pre-implantation mouse uterus, and cell-specific regulation of IGF-I gene expression by estradiol and progesterone Biology of Reproduction 46 208-219

Matsuda T, Hirano T, Nagasawa $\mathrm{S}$ and Kishimoto $\mathrm{T}$ (1989) Identification of alpha2-macroglobulin as a carrier for IL-6 Journal of Immunology $\mathbf{1 4 2}$ 148-152

Murphy LJ, Murphy LC and Freisen HG (1987) A role for the insulin-like growth factors as estromedins in the rat uterus Transactions of the Association of American Physicians 99 204-214

Rosenfeld RG, Lamson G and Pham H (1990) Insulin-like growth factor binding proteins Recent Progress in Hormone Research 46 99-163

Rotwein P (1991) Structure, evolution, expression, and regulation of insulinlike growth factors I and II Growth Factors 5 3-18

Shimasaki S and Ling N (1991) Identification and molecular characterization of insulin-like growth factor binding proteins (IGFBP-1, -2, -3, -4, -5, and -6) Progress in Growth Factor Research 1 243-266

Unterman TG, Oehler DT, Gotway MB and Morris PW (1990) Production of the rat type $I$ insulin-like growth factor-binding protein by well differentiated H4EIIC 3 hepatoma cells: identification, purification, and N-terminal amino acid analysis Endocrinology 127 789-797

Downloaded from Bioscientifica.com at 04/26/2023 01:09:24PM 
Unterman TG, Simmons RA, Glick RP and Ogata ES (1993) Circulating levels of insulin, insulin-like growth factor-I (IGF-I), IGF-II, IGF-binding proteins in the small for gestational age fetal rat Endocrinology 132 327-336

Waites GT, James RFL and Bell SC (1988) Immunohistological localization of the human endometrial secretory protein pregnancy-associated endometrial a1-globulin, an insulin-like growth factor-binding protein, during the menstrual cycle Joumal of Clinical Endocrinology and Metabolism 671100 1104
Waites GT, James RF and Bell SC (1989) Human 'pregnancy-associated endometrial alpha 1-globulin', an insulin-like growth factor-binding protein: immunohistological localization in the decidua and placenta during pregnancy employing monoclonal antibodies Joumal of Endocrinology $\mathbf{1 2 0}$ 351-357

Welsh AO and Enders AC (1983) Occlusion and reformation of the rat lumen during pregnancy American Joumal of Anatomy 167 463-477 